\title{
PREVALENCIA DE Trypanosoma vivax EN BOVINOS DE LA PROVINCIA DE CORONEL PORTILLO, UCAYALI
}

\author{
Patricia Quispe A. ${ }^{1}$, Amanda Chávez V. ${ }^{2,3}$, Eva Casas A. ${ }^{2}$, Antonio Trigueros V. ${ }^{4}$ \\ y Francisco Suárez A. 5
}

\section{Abstract}

The objective of the study was to determine the prevalence of Trypanosoma sp. in healthy cattle that are reared in four districts (Callería, Campo Verde, Masisea and Yarina) of the Coronel Portillo Province, Ucayali, using the Woo and the buffy coat stained with Giemsa techniques. The latter was also used to determine the species of trypanosome involved. A total of 289 blood samples were collected in May-July, 2000 from crossbred Zebu cattle. Animals were 8 months till 16 years of age, and managed under an extensive rearing system. The morphometric identification showed that the prevalent species was Trypanosoma vivax. The prevalence of T. vivax was $22.2 \pm 4.8 \%$ when the Woo technique was used and $5.9 \pm 2.7$ when the stained smear was used. The Campo Verde district had the higher frequency of positive animals $(97 \%, 62 / 64)$. None of the animals showed clinical signs of the disease and only 8 animals had a low hematocrit value. No significant relationship between the presence of the parasite and the low hematocrit was found ( $p>0.05)$. It was concluded that the observed prevalence was relatively high, whereas animals have a subclinic or benign infection.

Key word: Trypanosoma sp., bovine, Trypanosoma vivax, haemoparasite, Ucayali

\section{Resumen}

El objetivo del estudio fue determinar la prevalencia de Trypanosoma sp. en bovinos aparentemente sanos de cuatro distritos (Callería, Campo Verde, Masisea y Yarina) de la provincia de Coronel Portillo, Ucayali, a través de las técnicas de Woo y el frotís delgado de "buffy coat" coloreado con Giemsa; usándose además este último para determinar la especie de tripanosoma involucrado. Se examinó muestras de sangre colectada entre mayo a julio del 2000 de 289 bovinos de cruces cebuinos, con edades entre 8 meses y 16 años, criados en forma extensiva. La identificación morfométrica determinó que la especie prevalente era Trypanosoma vivax. Se obtuvo una prevalencia de $T$. vivax mediante la técnica de Woo de $22.2 \pm 4.8 \%$ y mediante la técnica de frotís coloreado de $5.9 \pm$ 2.7\%. El distrito de Campoverde presentó la mayor frecuencia de animales positivos $(97 \%, 62 / 64)$. Ningún animal mostró signos de la enfermedad y sólo 8 tuvieron hematocrito bajo. No se encontró relación estadística entre la presencia del parásito y el hematocrito bajo ( $p>0.05$ ). Se concluyó que la prevalencia hallada fue medianamente alta, siendo la infección aparentemente subclínica o benigna.

Palabras clave: Trypanosoma sp., bovinos, Trypanosoma vivax, hemoparásito, Ucayali

${ }^{1}$ Práctica privada

${ }^{2}$ Laboratorio de Microbiología y Parasitología Veterinaria, FMV-UNMSM

${ }^{3}$ E-mail: a_chavez_g@hotmail.com

${ }^{4}$ Estación Experimental del Centro de Investigación IVITA-Pucallpa, FMV-UNMSM

${ }^{5}$ Laboratorio de Medicina Veterinaria Preventiva, FMV-UNMSM 


\section{INTRODUCCIÓN}

Los tripanosomas son parásitos unicelulares que infectan tanto a animales silvestres y domésticos como al hombre, pudiendo llegar a provocar la muerte dependiendo de la patogenicidad del parásito (Wells y Russell, 1973).

Esta enfermedad surgió en el continente africano, donde se ha convertido en una de las principales limitantes para el desarrollo de la ganadería (Connor et al., 1986). Los principales tripanosomas causantes de enfermedad en los animales domésticos son: $T$. congolense, T. vivax, T. brucei, T. evansi, T. equiperdum, T. simiae y $T$. theileri (Soulsby, 1987).

La presencia de los tripanosomas en el continente americano data desde principios del siglo pasado (Leger y Vienne, 1919), y actualmente su distribución abarca desde el Salvador y Costa Rica hasta Brasil y Paraguay, incluyendo algunas islas caribeñas como Guada lupe y M artinica (Betancourt et al., 1983; Clarkson, 1976). Los tripanosomas, junto con otros hemoparásitos (Anaplasma sp. y Babesia sp.) limitan la producción y la productividad ganadera en las zonas tropicales y subtropicales. Las especies involucradas son el $T$. vivax. y $T$. evansi (Cordero del Campillo y Rojo, 1999; Machado y Dávila, 1998; Muñoz y Chávez, 2001; Rojas, 1991).

En el Perú sólo existe un reporte de tripanosomosis en el año 1977 que ocurrió en vacas Santa Gertrudis en Pucallpa, donde el agente causal fue el Trypanosoma vivax (Calderón y Bazalar, 1978). Sin embargo, considerando que éste parásito junto con otros hemoparásitos son los causantes del mayor número de bajas en el ganado bovino en zonas tropicales y subtropicales de América Central y del Sur (Alva, 1998), se diseñó el presente estudio para evaluar la prevalencia de Trypanosoma sp. en bovinos aparentemente sanos de cuatro distritos (Callería, Campo Verde, Masisea y Yarina) de la pro- vincia de Coronel Portillo, departamento de Ucayali. Esta región está clasificada como bosque húmedo tropical, con una temperatura media anual de $26{ }^{\circ} \mathrm{C}$ y una precipitación promedio anual de $2,000 \mathrm{~mm}$.

\section{Material y MéTodos}

Se trabajó con bovinos de ambos sexos, con edades de 8 meses a 16 años, y mayormente cruces de Brown Swiss con Brahman y Nellore. Se colectó sangre en tubos con EDTA, que fue procesada por el método de Woo (microcapilar) y frotís del buffy coat (capa flogística) coloreado con Giemsa. Además se midió el hematocrito. Se consideraron muestras positivas a la técnica de Woo cuando los parásitos se movían en la interfase de la costra flogística y el plasma. Las muestras positivas a la técnica de frotís del buffy coat permitió además identificar a los parásitos en base a las características morfométricas reportadas en la literatura (Soulsby, 1987; Betancourt et al., 1983).

El tamaño muestral se calculó en base a la fórmula para la estimación de proporciones (Daniel, 1996) y para mejorar la estimación del parámetro se estratificó (Cochran, 1980) según la población distrital (Dirección Técnica de Censos y Encuestas, 1995).

El resultado de la prevalencia de la prueba se expresó en forma porcentual con intervalo de confianza del 95\%. Los resultados positivos mediante la prueba de Woo se analizaron por medio de la prueba de Chi cuadrado (Daniel, 1996), para establecer la relación entre la presencia del parásito y el nivel de hematocrito.

\section{Resultados y Discusión}

Las características morfométricas de los tripanosomas hallados por la técnica del frotís correspondieron a extremo posterior romo, kinetoplasto grande, membrana ondulante poco desarrollada, flagelo corto; y me- 
Cuadro 1. Distribución de Trypanosoma vivax en bovinos de 4 distritos de la provincia de Coronel Portillo. Abril-julio 2000

\begin{tabular}{|c|c|c|c|c|c|}
\hline \multirow{2}{*}{ Distrito } & \multirow{2}{*}{$\begin{array}{c}\text { Animales } \\
\text { muestreados }\end{array}$} & \multicolumn{2}{|c|}{ Woo } & \multicolumn{2}{|c|}{ Frotís } \\
\hline & & (n) & $\%$ & $\mathrm{n}$ & $\%$ \\
\hline Callería & 26 & 0 & - & 0 & - \\
\hline Campo Verde & 205 & 62 & 97.0 & 16 & 94.0 \\
\hline Masisea & 24 & 1 & 1.5 & 0 & - \\
\hline Yarina & 34 & 1 & 1.5 & 1 & 6.0 \\
\hline Total & 289 & 64 & 22.2 & 17 & 5.9 \\
\hline
\end{tabular}

didas que variaban de 31.2 a $40.3 \mu \mathrm{m}$, los cuales corresponden al Trypanosoma vivax, aunque con medidas superiores a los estándares descritos por Hoare (1972). Este diagnóstico fue confirmado por el Instituto Oswaldo Cruz de Brasil.

Se halló una prevalencia de Trypanosoma vivax en 289 muestras de $22.2 \pm 4.8 \%$ y $5.9 \pm 2.7 \%$ mediante la técnica de Woo y frotís coloreado, respectivamente. La diferencia de animales positivos entre ambas pruebas se debe probablemente a la sensibilidad de las pruebas, toda vez que la sensibilidad del diagnóstico con frotís delgado es de $10 \%$ (Botero, 1998), y con la técnica de Woo se ha demostrado que es superior al $60 \%$ (Desquesnes, 1997). Cabe mencionar que la técnica de Woo se utilizó básicamente para determinar la prevalencia mientras que la técnica de frotís tuvo como principal objetivo identificar la especie de tripanosoma, ya que permite una mejor visualización de las estructuras del parásito.

El moderado nivel de infección encontrado puede atribuirse a la existencia de condiciones que favorecen la presencia y difusión de esta parasitemia, tales como la pobre condición corporal de la mayoría de los animales muestreados, el tipo de manejo sanitario deficiente, donde por ejemplo se emplea una misma aguja en diferentes animales, y por último, la imposibilidad de controlar a los insectos hematófagos, principales transmisores de la enfermedad.

La mayor frecuencia de animales positivos a Tripanosoma vivax provino del distrito de Campo Verde (Cuadro 1). La mayor proporción de animales infectados en este distrito puede atribuirse a la gran población de hospederos susceptibles presentes en el área, ya que el mayor número de ganado vacuno europeo (Brown Swiss principalmente y Holstein) y sus cruces se encuentran en este distrito (Dirección Técnica de Censos y Encuestas, 1995); además, constituye una de las zonas donde ocurren los mayores intercambios comerciales de ganado en pie (Betancourt et al., 1983; Dávila et al., 1997).

Treinta y cinco de los 64 bovinos positivos a la prueba de Woo mostraron una condición corporal pobre, dos tenían las mucosas pálidas y ocho presentaron un hematocrito menor al 24\%. No se encontró asociación estadística significativa entre la presencia del parásito y el valor del hematocrito (aceptable o bajo). La causa del bajo nivel de hematocrito, aún en los animales negativos a la prueba de Woo, y el pobre regular estado de carnes, podría deberse a la presencia de otros agentes tales como, parásitos gastro- 
intestinales, otros hemoparásitos, etc., así como a deficiencias nutricionales.

La ausencia de un estado patológico por causa del Trypanosoma vivax podría estar relacionado a la susceptibilidad del hospedero o patogenicidad del tripanosoma. Es posible que la predominancia de sangre cebuína en estos animales los haga menos susceptibles a desarrollar la enfermedad (Betancourt et al., 1983); también podría caber la posibilidad que en la región predomine una subespecie o cepa de baja patogenicidad, adaptada a los bovinos del lugar (Rojas, 1991). Esta situación no es un caso aislado; así, en zonas endémicas de Colombia y Venezuela se han reportado infecciones que pueden cursar sin signos clínicos (Wells et al., 1982; Tamasaukas y Roa, 1993).

Los resultados de este estudio demuestran que la prevalencia del Trypansoma vivax en cuatro distritos de la provincia de Coronel Portillo fue medianamente alta, por lo que se debería realizar estudios similares en otras áreas ganaderas de clima tropical y subtropical para conocer la real distribución de la tripanosomiasis, utilizando no solo técnicas parasitológicas, sino además técnicas serológicas de mayor sensibilidad y especificidad.

\section{Literatura Citada}

1. Alva, B. 1998. Seroprevalencia de Babesia bovis en bovinos del distrito de Oxapampa. Tesis de Bachillerato. Facultad de Medicina Veterinaria, Univ. Nacional Mayor de San Marcos, Lima. 37 p.

2. Betancourt, A.; E. Wells; L. Ramirez. 1983. Tripanosomiasis de los animales domésticos en Colombia. Contribución del Programa de Parasitología y Entomología Veterinaria del Instituto Colombiano Agropecuario. p 1-39.

3. Botero, D. 1998. Parasitosis humanas. $3^{\text {ra }}$ ed. p 203-432. Ed. Rojo. Colombia.
4. Calderón G.; H. Bazalar. 1978. Presencia de Trypanosoma vivax en ganado vacuno de Pucallpa. Bol. Soc. Per. Parasitol. Lima 1: 5.

5. Clarkson, J. 1976. Trypanosomiases of domesticated animals of South America. Trans. Royal Soc. Trop. Med. Hyg. 70: 125-126.

6. Cochran, W. 1980. Técnicas de muestreo. p 235. Ed. CECSA. España.

7. Connor, M.; D. Olatunde; S. Akpavie; M. Murray. 1986. African animal trypanosomiases. Annual Report, Department of Veterinary Services and Animal Husbandry. Lusaka.

8. Cordero de Campillo, M.; V. Rojo. 1999. Parasitología Veterinaria. p 302309. Ed. Mc Graw-Hill. México.

9. Daniel, W. 1996. Bioestadística, bases para el análisis de las ciencias de la salud. $5^{\text {ta }}$ ed. p 206. Noriega Editores. México.

10. Dávila, A.; M. Silva; A. Jenson. 1997. Dynamics of Trypanosoma evansi outbreaks in the Pantananal, Brasil. Proceeding of the First Internet Conference on Salivarian Trypanosome. Roma. p 12-13.

11. Desquesnes, M. 1997. Evaluation of simple PCR technique for the diagnosis of Trypanosoma vivax infection in the serum of cattle in comparison to parasitological techniques and antigenenzyme-linked immuno sorbent assay. Acta Trop. 65: 139-148.

12. Dirección Técnica de Censos y Encuestas. 1995. III Censo Nacional Agropecuario. Resultados Definitivos. Departamento de Ucayali. 2: 687-689.

13. Hoare, C. 1972. The trypanosomes of mammals. A zoological monograph. Blackwekk Scientific Publication. Oxford. $749 \mathrm{p}$.

14. Leger, M.; M. Vienne. 1919. Epizootie a trypanosomes chez les bovides de la Guyan Francaise. Bul. Soc. Pathol. Exot. 12: 258-266.

15. Machado, R.; A. Dávila. 1998. Carrapato, tristeza parasitária e tripanossomase dos bovinos. p 123-157. EMBRAPA-CNPGC. Brasil. 
16. Muñoz, K.; A. Chávez. 2001. Trypanosoma evansi isolated from capibara (Hidrochaeris hidrochaeris). Mem. Inst. Oswaldo Cruz, Rio de Janeiro. 96: 945-946.

17. Rojas, M. 1991. Parasitismo de los rumiantes domésticos: terapia, prevención y modelos para su aprendizaje. p 302306. Ed. Maijosa. Perú.

18. Soulsby, J. 1987. Parasitología y enfermedades parasitarias. $7^{\mathrm{a}}$ ed. p 521-533. Ed. Interamericana. México.
19. Tamasaukas, R.; N. Roa. 1993. Seroprevalencia de la tripanosomiasis bovina (Trypanosoma vivax) en el estado Guarico, Venezuela. Libro de Resúmenes XI Congreso Latinoamericano de Parasitología. Perú. p 133.

20. Wells, E.; A. Betancourt; L. Ramírez. 1982. Trypanosoma vivax in Colombia: interpretation of field results. Trop. An. Health. Prod. 14: 141-150.

21. Wells, E.; H. Russell.1973. Enfermedades parasitarias de los mamíferos salvajes. p 363-379. Ed. Acribia. España. 